\title{
The Importance of Countering Biosimilar Disparagement and Misinformation
}

\author{
Hillel P. Cohen ${ }^{1}$ (D) Dorothy McCabe ${ }^{2}$
}

Published online: 20 July 2020

(c) The Author(s) 2020

\begin{abstract}
Biosimilar use is limited in some healthcare systems because biosimilars are not well understood by many healthcare professionals and patients. The knowledge gap is exacerbated by disparagement of biosimilars and dissemination of misinformation, whether intentional or otherwise. There are several different types of disparagement and misinformation directed towards biosimilars as a class, including statements about biosimilar science or policy that are factually incorrect; misleading information, where the information is correct, but is provided out of context; incomplete information, where only partial or a limited set of facts are provided; creation of a false narrative, especially in scientific and medical literature, that provides a set of references to support incorrect conclusions; and negative message framing of factual statements to create a negative perception. Disparagement and misinformation about biosimilars can be countered by educational efforts, appropriate oversight, and regulatory activities with the option of enforcement action by governmental agencies, if warranted. Balanced educational materials about biosimilars should be made easily accessible. Physicians, nurses, pharmacists, and patient advocacy groups should work together to provide patients with consistent, positive messages about the value of biosimilars.
\end{abstract}

\section{Key Points}

Biosimilars will contribute to multiple-source biologics markets when they are allowed to compete fairly with their reference products.

There are several different types of disparagement and misinformation directed against biosimilars, individually and collectively, that are impeding their ability to contribute to a sustainable multiple-source biologics market.

Disparagement and misinformation about biosimilars can be countered by balanced educational outreach across stakeholders, appropriate regulatory oversight, and use of enforcement powers already granted to government agencies.

\footnotetext{
Hillel P. Cohen

hillel.cohen@sandoz.com

Sandoz Inc., Princeton, NJ, USA

2 Boehringer Ingelheim, Ridgefield, CT, USA
}

\section{Introduction}

Biosimilar drugs developed to the standards of the European Medicines Agency (EMA), the US Food and Drug Administration (FDA), or the World Health Organization (WHO) offer multiple benefits at patient and societal levels [1]. Biosimilars are viable treatment options because they provide the same safety and efficacy as their reference biologic products [2-4]. In some healthcare systems, availability of biosimilars has expanded patient access to optimal treatment and increased the sheer number of patients receiving care [5]. In addition, competition from biosimilars has led to lower overall costs for both reference biologics and biosimilars. In some locales, biosimilar savings have enabled health plans to cover additional drugs or hire more healthcare professionals (HCPs) [6, 7].

Despite these benefits, biosimilar use is still limited in some healthcare systems because they are not well understood by many HCPs and patients [8]. This mistrust is exacerbated by negatively biased information disseminated by some parties [9, 10], some of which was observed as early as 2013 [11]. In this Current Opinion article, we examine the challenges that biosimilars face due to disparagement and dissemination of misinformation, whether intentional or otherwise. To our knowledge, this is the first detailed 
analysis of this topic as it pertains to biosimilars. Examples are provided for each category, but they are not intended to be an exhaustive list.

\section{Conceptual Challenges}

There are conceptual differences between reference biologics and biosimilars that may not be well understood. Surveys of physicians and patients have revealed knowledge shortcomings and highlight the need for further education on biosimilar drug development and approval $[12,13]$.

\subsection{Product Variability}

HCPs are generally unaware that all biologics, especially those with post-translational modifications, are complex mixtures of related molecular variants that share the same amino acid sequence and that there is inherent batch-tobatch variability among both reference biologic products and biosimilars because they are produced in genetically engineered living cells [12]. This heterogeneity is controlled during manufacturing, and the extent of heterogeneity is quantified via process and product testing [14]. With a lack of understanding of this fact, the term "biosimilar" can be problematic because "similar" can be misunderstood as implying a difference of some sort. It may be conceptually difficult to appreciate that a copy product can provide the same clinical outcome even if it is not absolutely identical in structure to its reference product, which as noted above can have batch-to-batch variability and can even vary within a batch.

\subsection{Abbreviated Licensure Pathway}

Biosimilar approvals in the USA are developed using "an abbreviated licensure pathway," a term used by the FDA in their implementation guidances and in their educational documents that describe the US Biologics Price Competition and Innovation Act of 2009 (BPCIA) [15, 16]. The term "abbreviated" could be perceived as being less rigorous or "more relaxed" [17]; however, this does not mean that a lower standard of approval is applied to biosimilar or interchangeable products than to reference biological products. As explained by the FDA, abbreviated licensure refers to "the ability to rely on FDA's previous finding regarding the reference product to support approval of the biosimilar product allows for a potentially shorter and less costly (clinical) drug development program" [18].

\subsection{Totality of Evidence}

Biosimilars are approved based on "the totality of evidence," with analytical analysis as the foundation and clinical safety and efficacy studies conducted as needed only to confirm the similarity already established through direct structural, functional, and pharmacokinetic/pharmacodynamic (PK/ PD) comparisons of the reference biologic and biosimilar. This differs from originator biologic approvals, which are typically developed and approved based on phase 3 safety and efficacy studies conducted individually for each indication $[18,19]$. Approval based on totality of evidence is a new concept for HCPs.

\subsection{Clinical Data}

HCPs routinely review data from clinical studies to understand the outcomes that they can expect for their patients. The data expectations for biosimilars are novel and different from what HCPs have been trained to accept for the reference biologics that biosimilars are designed to match. Clinical safety and efficacy studies conducted with biosimilars are designed to confirm the biosimilarity that was established by use of structural, functional, and PK/PD methods. As a result, the endpoints in clinical studies used to establish biosimilarity may be different from those used in the studies used to approve the reference product. And in general, there are fewer clinical studies conducted with a biosimilar compared to its reference product. While the clinical data package supporting biosimilar approval is more streamlined compared to the reference product, the overall data package is equally rigorous $[18,19]$. Furthermore, it is misleading to compare data packages across biosimilars, as different developers of biosimilars to the same reference product may elect to use different study designs or even study different indications.

\subsection{Extrapolation}

The concept of extrapolation may be difficult to understand in the context of biosimilars. Extrapolation of indications is based on structural and functional similarity and PK/PD data, and not between the indications of the reference product [18]. It is understandable that patients and their healthcare providers might prefer a drug explicitly studied in each indication when they lack an understanding and appreciation of how extrapolation is applied towards biosimilars. However, extrapolation is a scientific principle that has been used widely for decades in other regulatory settings, most notably in the development of chemical and biological drugs when manufacturers seek to modernize one or more steps used in synthesis, fermentation, purification, or formulation [20]. 


\subsection{Wording of Legislation}

The wording of legislation can be confusing. The BPCIA specifies that biosimilars must have "no clinically meaningful differences between the biological product and the reference product in terms of the safety, purity, and potency of the product" [15]. This is slightly different wording when compared to one of the criteria for interchangeability, a US regulatory designation that is different from biosimilarity. Interchangeability is a designation that is specific for the US and means a biosimilar may be substituted by a pharmacist for the reference product without the intervention of the HCP who wrote the prescription, consistent with state law [21]. The BPCIA specifies that interchangeable biologics are (1) biosimilars that "can be expected to produce the same clinical result as the reference product in any given patient" [15], and that (2) there is no clinical impact if patients switch back and forth multiple times between reference biologic and interchangeable biologic. In their guidance on the topic, the FDA has stated that unless explicitly agreed upon otherwise, a distinct clinical PK or PD switching study will be required to demonstrate interchangeability [21]. In our opinion, the use of similar wording that is functionally identical for biosimilarity and for the first of the two criteria for interchangeability has led to confusion in the USA in understanding the difference between biosimilarity and interchangeability.

\section{Types of Biosimilar Disparagement and Misinformation}

An analysis of negative and inaccurate information disseminated about biosimilars reveals several different types of disparagement and misinformation directed towards biosimilars as a class of products (Table 1).

\subsection{Statements About Biosimilar Science or Policy that are Factually Incorrect}

Factually incorrect information is often directed at one aspect of the biosimilar pathway or data supporting biosimilars. For example, one of the strongest sets of data supporting biosimilars is the extensive safety monitoring of biosimilars in the EU since the region's first biosimilar approval in
2006. With over 700 million patient days of exposure as of 2019 [22], the EMA concluded that "over the last 10 years, the EU monitoring system for safety concerns has not identified any relevant difference in the nature, severity or frequency of adverse effects between biosimilars and their reference medicines" [23]. Nonetheless, claims have been made that the EU pharmacovigilance monitoring of biosimilars is inadequate and patients cannot be confident about the reliability of these data $[24,25]$. If believed, this could cause some to dismiss the extensive EU safety experience with biosimilars and could lead to unwarranted concerns about their safety. The fact is that these assertions are far from the truth [26]. There are many EU countries with sizable populations that have advanced pharmacovigilance systems that are as excellent as any pharmacovigilance system in the world [27]. The EMA and the FDA have been emphatic that HCPs and patients can be reassured that biosimilars approved in the EU and the USA are as safe and effective for their intended use as their respective reference medicines $[18,23]$.

Another common but incorrect assertion is that in the USA, interchangeability is a higher quality standard than biosimilarity [28]. The FDA has been clear that there is only a single set of quality standards for drugs of biological origin [18]. A designation of interchangeability is intended by statute to meet a regulatory standard that would enable substitution by the pharmacist in either a retail or specialty pharmacy setting without the intervention of the HCP who prescribed the reference product [21]. It is a different regulatory category compared to biosimilarity and requires additional and different clinical data. But the quality standards for biosimilars and interchangeable biologics are absolutely identical.

\subsection{Misleading Information, Where the Information is Correct but is Provided Out of Context}

At times, biosimilar information is provided that is correct but presented out of context, causing a misleading impression. Claims have been made that while biosimilar infliximabs are available, there are no "interchangeable" biosimilar infliximabs available in the USA [29]. While this is factually correct because the FDA has not yet approved

Table 1 Types of biosimilar disparagement and misinformation

1. Statements about biosimilar science or policy that are factually incorrect

2. Misleading information, where the information is correct but is provided out of context

3. Incomplete information, where only partial or a limited set of facts are provided

4. Creation of a false narrative, especially in scientific and medical literature, that provides a set of references to support incorrect conclusions

5. Negative framing of factual statements to create a negative perception 
an interchangeable biologic, it is misleading as a scientific and clinical matter. Such claims do not provide the full context that in the USA an interchangeability designation is only relevant for drugs administered in a retail or specialty pharmacy setting [21]. Infliximabs are administered by a provider in out-patient clinics or in doctors' offices. In these non-retail settings, US pharmacists do not have the ability to substitute reference biologics and biosimilars. As a result, there is no practical application for pharmacist-mediated interchangeability of infliximabs in US hospitals, out-patient clinics, or physician offices, so there is no reason for a manufacturer of biosimilar infliximab to seek a US interchangeability designation. It is interesting to note that the FDA and the EMA agree that for purposes of physician prescribing, all approved biosimilars may be freely substituted by prescribing physicians without the need for additional clinical switching studies [29].

\subsection{Incomplete Information, Where Only Partial or a Limited Set of Facts are Provided}

Misleading perceptions can be created when only a limited portion of facts are shared without providing full details. For example, statements noting that biosimilars are not identical to their reference products are common [30, 31]. But these often omit the important fact that there is inherent batch-tobatch variability for all biologics, including reference biologics currently on the market. When making manufacturing changes to currently approved biologics, reference companies are required to complete a comparability exercise that is similar to the analytical comparisons done for the development of a biosimilar [14]. It should be reassuring to HCPs to know that health authorities require pre-defined limits for batch-to-batch variability of all biologics, including both originator biologics and biosimilars [32].

\subsection{Creation of a False Narrative that Provides a Set of References to Support Incorrect Conclusions}

Incorrect or misleading conclusions about biosimilars have been published in scientific literature, enabling others to quote the misleading conclusions as fact and creating a false narrative. An article on the ethics of biosimilars [33] cited three literature reviews [34-36] to conclude that the safety and efficacy of switching once from a reference product to a biosimilar is still controversial, and therefore physicians are ethically obligated to inform prospective biosimilar recipients of this "fact." However, a close examination of the three reviews found that none of them identified any specific safety or lack of efficacy concern related to switching once from a reference biologic to a biosimilar. Another recent review of 178 switching studies also concluded that for the products studied, a single switch is not intrinsically linked to an increase in immunogenicity, safety, or efficacy issues [37]. Nonetheless, the "fact" that there is a supposed controversy about the practice of switching from a reference biologic to a biosimilar was cited by another publication as part of a set of arguments against a Canadian provincial policy of switching from reference infliximab to biosimilar infliximab [38]. There is no scientific controversy about the practice of switching [39], but the false narrative persists.

\subsection{Negative Framing of Factual Statements to Create a Negative Perception}

Negative message framing of factual statements can also create a negative perception. As cited previously, one example is that biosimilars are highly similar but not identical to their reference products, which can be understood as implying a difference of some sort. The impact of message framing on biosimilar use was evaluated in a recent study that compared patient responses to a hypothetical switch from a reference biologic to a biosimilar that was accompanied with either positive or negative framing [40]. The authors found a greater patient willingness to switch to a biosimilar if the switch was explained to them by physicians (1) who emphasized the similarities between reference product and biosimilar and (2) who used positive body language and verbal cues to promote a positive interaction. In a real-world assessment of patient outcomes after switching to biosimilar infliximab or biosimilar etanercept, a study found higher acceptance and persistence rates after switching to a biosimilar when patients received an enhanced and coordinated communications strategy across the entire patient healthcare team that included positive messaging [41]. It has been demonstrated that negative perceptions may lead to negative outcomes, a phenomenon known as the nocebo effect [42-44].

Another example of negative framing is the pervasive use of the term "non-medical switching" or "non-medical substitution" when describing the transition from reference product to a biosimilar. This phrase has been used by both publications that support this practice as well as by those that warn against it $[38,45]$. However, the terms non-medical switching and non-medical substitution actually refer to formulary-driven changes between drug options that are thought to be therapeutically equivalent, but that are very different in structure [46]. In contrast, biosimilars are proven to be highly similar in both structure and function to their reference products. Because a transition from a reference product to a biosimilar is between two highly similar products that health authorities have explicitly found to have no meaningful clinical differences, the concept and terms of non-medical switching and non-medical substitution do not apply to biosimilars [47]. The common but inappropriate use of these terms in respect to biosimilars conveys a negative connotation regarding switches to patients and their 
HCPs when in fact such switches may be very beneficial in increasing access and possibly lowering costs to individual patients [47]. This was quantified in a survey that reported that $60 \%$ of EU physicians were either very comfortable or comfortable in switching of stable patients to biosimilars, but when the very same question was posed with the phrase "non-medical switching" inserted, the percentage declined to $42 \%$ [48].

\section{Potential Impact of Biosimilar Disparagement and Misinformation}

Biosimilar disparagement and misinformation has a very real potential to slow adoption of biosimilars, diminishing opportunities to increase patient access and help generate healthcare system savings on pharmaceutical expenditures [9, 49].

Continued dissemination of disparaging, misleading, or incorrect information may lead to unwarranted concerns that patients will not attain maximal efficacy on a biosimilar or may have an adverse event that they would not have had with the reference biologic [43, 44, 50].

An HCP's lack of trust about the safety and effectiveness of biosimilars may be reflected in the manner and tone of conversations that they have with their patients [50].

Biosimilar disparagement and misinformation may cause patients to fear that they will receive an ineffective, inferior, or unsafe product. Patients could specifically request not to be treated with a biosimilar, or if they do receive a biosimilar, a negative preconceived opinion of the biosimilar may lead to poor clinical outcomes [43, 44, 50].

\section{Steps to Overcome Biosimilar Disparagement and Misinformation}

Biosimilar disparagement and misinformation will continue unless it is challenged; we cannot ignore these activities. It is the responsibility of all stakeholders to challenge biosimilar disparagement and misinformation when encountered. Clear and unbiased scientific messaging will help biosimilars become widely accepted by patients and their HCPs as valid therapeutic options. Fortunately, authorities at the FDA and the US Federal Trade Commission have acknowledged that biosimilar disparagement and misinformation may exist and are considering steps to counter any such activity and to support the nascent biosimilar industry [51, 52]. This is not a US-specific concern, as biosimilar disparagement and misinformation may also be encountered in Europe and other developed or developing economic markets [53]. The public should be encouraged to report examples of potential biosimilar disparagement and misinformation that are observed or encountered to health authorities and other governmental bodies with oversight. These bodies would then evaluate the report and take actions if appropriate [54].

Reviewers and editors of scientific journals and trade publications have a responsibility to rigorously review biosimilar articles submitted for publication to ensure that they are truthful and balanced.

Education with a focus on clarity is critical to dispelling these activities. There are a multitude of educational materials already developed by health authorities, professional societies, patient advocacy groups, and industry [23, 55-63]. A cascade of verified information from these groups to patients will help allay patient concerns and support biosimilar acceptance. These efforts are already ongoing, but must be accelerated and amplified.

Biosimilar education should be incorporated into curricula of all medical, nursing, and pharmacy schools [64].

Key sources of information about biosimilars should be provided in graphical format and in locations that are easily accessible and understandable to the public [65-67]. Patients frequently use internet search engines as their first stop in seeking information [68, 69].

Positive framing of key concepts will help address disparagement by highlighting the quality and benefits of biosimilars. Positive framing will also lead to supportive overall narratives that could encourage biosimilar use [40-44, 50].

\section{Conclusion}

The negative impact of slower than initially anticipated uptake of biosimilars should not be underestimated. Patient health and the fiscal sustainability of healthcare systems are at stake. Furthermore, the importance of countering biosimilar disparagement and misinformation should not be dismissed based on an increase in uptake of some biosimilars, although it varies by both country and product [ 70 , 71], because that would give license for the disparagement and misinformation to continue and ignores the long-term impact on HCP and patient trust.

Although there are multiple contributing factors [49], the slow uptake of biosimilars is likely due in part to the fact that patients and HCPs have at times been subjected to misleading, incomplete, out-of-context, and at times incorrect information about biosimilars. These activities can be countered by educational activities from respected sources and by regulatory actions. National authorities and governmental agencies with appropriate oversight should monitor to prevent dissemination of misinformation with the option of taking enforcement action if warranted. Balanced, educational materials about biosimilars should be 
made easily accessible, and physicians, nurses, pharmacists, and patient advocacy groups should work together to provide patients with consistent, positive messages about the value of biosimilars.

Acknowledgements The authors thank Saiza Elayda and Julie Zawisza of Merck, Kim Campbell and Jeffrey Robinson of Sandoz, and Robert Popovian of Pfizer for their helpful comments.

Author Contributions Hillel P. Cohen wrote the initial draft and Dorothy McCabe edited the manuscript. Both authors finalized the manuscript together and take responsibility for the content.

\section{Compliance with Ethical Standards}

Funding No funding was received by the authors for preparation of this article. The Biosimilars Forum, a US-based biosimilars trade association, provided funding to make this publication available to the public via Open Access.

Conflict of interest Hillel P. Cohen is an employee of Sandoz Inc., a division of Novartis and may own stock in Novartis. Dorothy McCabe is an employee of Boehringer Ingelheim. Hillel P. Cohen and Dorothy McCabe are co-chairs of the Education Committee of the Biosimilars Forum. The views expressed here are those of the authors in their roles with the Biosimilars Forum and not of their respective companies.

Availability of data and material Not applicable.

Code availability Not applicable.

Open Access This article is licensed under a Creative Commons Attribution-NonCommercial 4.0 International License, which permits any non-commercial use, sharing, adaptation, distribution and reproduction in any medium or format, as long as you give appropriate credit to the original author(s) and the source, provide a link to the Creative Commons licence, and indicate if changes were made. The images or other third party material in this article are included in the article's Creative Commons licence, unless indicated otherwise in a credit line to the material. If material is not included in the article's Creative Commons licence and your intended use is not permitted by statutory regulation or exceeds the permitted use, you will need to obtain permission directly from the copyright holder. To view a copy of this licence, visit http://creativecommons.org/licenses/by-nc/4.0/.

\section{References}

1. Dutta B, Huys I, Vulto AG, et al. Identifying key benefits in European off-patent biologics and biosimilar markets: it is not only about price! BioDrugs. 2019. https://doi.org/10.1007/s40259-01900395-w.

2. European Medicines Agency. Guideline on similar biological medicinal products. CHMP/437/04 Rev 1. http://www.ema.europ a.eu/docs/en_GB/document_library/Scientific_guideline/2014/10/ WC500176768.pdf. Accessed 16 Mar 2020.

3. US Food and Drug Administration. Biosimilars: questions and answers regarding implementation of the Biologics Price Competition and Innovation Act of 2009: guidance for industry. https ://www.fda.gov/media/119258/download. Accessed 16 Mar 2020.
4. WHO Expert Committee on Biological Standardization-Technical Report Series 977: Annex 2-guidelines on evaluation of similar biotherapeutic products (SBPs). https://apps.who.int/ medicinedocs/documents/s19941en/s19941en.pdf. Accessed 16 Mar 2020.

5. Winegarden $\mathrm{W}$. Incenting competition to reduce drug spending: the biosimilar opportunity. Pacific Research Institute. 2019. https ://www.pacificresearch.org/wp-content/uploads/2019/07/Biosi milarsCompetition_F.pdf. Accessed 16 Mar 2020.

6. European Specialist Nurses Organisations: Switch management between similar biological medicines. 2018. http://www.esno.org/ assets/biosimilar-nurses-guideline-final.pdf. Accessed 16 Mar 2020.

7. Razanskaite V, Bettey M, Downey L, et al. Biosimilar infliximab in inflammatory bowel disease: outcomes of a managed switch programme. J Crohns Colitis. 2017;11(6):690-6.

8. Frapaise FX. Biosimilars: patient perspectives, challenges and emerging solutions: current opinions. J Drug Res Dev. 2019. https ://doi.org/10.16966/2470-1009.148.

9. Citizen Petition from Pfizer Inc. August 22, 2018. https://www. regulations.gov/document?D=FDA-2018-P-3281-0001. Accessed 19 Mar 2020.

10. Cohen HP, McCabe D. Combatting misinformation on biosimilars and preparing the market for them can save the U.S. billions. Stat News-First Opinion. June 18, 2019. https://www.statnews. com/2019/06/19/misinformation-biosimilars-market-preparation. Accessed 16 Mar 2020.

11. Building a wall against biosimilars. Nat Biotechnol. 2013. 31:264. https://doi.org/10.1038/nbt.2550.

12. Cohen H, Beydoun D, Chien D, et al. Awareness, knowledge, and perceptions of biosimilars among specialty physicians. Adv Ther. 2016;33:2160-72.

13. Peyrin-Biroulet L, Lonnfors S, Avedano L, et al. Changes in inflammatory bowel disease patients perspectives on biosimilars: a follow-up survey. United Eur Gastroenterol J. 2019;7(10):1345-52.

14. Lamanna WC, Holzmann J, Cohen HP, et al. Maintaining consistent quality and clinical performance of biopharmaceuticals. Expert Opin Biol Ther. 2018;18(4):369-79.

15. Improving Access to Innovative Medicinal Therapies. Biologics price competition and innovation. https://www.fda.gov/media /78946/download. Accessed 16 Mar 2020.

16. US Food and Drug Administration. Scientific considerations in demonstrating biosimilarity to a reference product. 2015. https:// www.fda.gov/regulatory-information/search-fda-guidance-docum ents/scientific-considerations-demonstrating-biosimilarity-refer ence-product. Accessed 18 May 2020.

17. Liu Y, Yang M, Garg V, et al. Economic impact of non-medical switching from originator biologics to biosimilars: a systematic literature review. Adv Ther. 2019;36:1851-77. https://doi. org/10.1007/s12325-019-00998-3. Accessed 17 Mar 2020.

18. Christl L, Lim S. Biosimilar and interchangeable products in the United States: scientific concepts, clinical use, and practical considerations. https://www.fda.gov/media/122832/download. Accessed 16 Mar 2020.

19. Cohen HP, Lamanna WC, Schiestl M. Totality of evidence and the role of clinical studies in establishing biosimilarity. In: Gutka HJ, Yang H, Kakar, editors. Biosimilars: regulatory, clinical and biopharmaceutical development, vol. 34., AAPS Advances in Pharmaceutical SciencesSwitzerland: Springer Nature; 2018. p. 601-28.

20. Krendyukov A, Schiestl M. Extrapolation concept at work with biosimilar: a decade of experience in oncology. EMSO Open. 2019;3:e000319. https://doi.org/10.1136/esmoopen-2017-00031 9. Accessed 16 Mar 2020 
21. U.S. Food and Drug Administration. Considerations in demonstrating interchangeability with a reference product guidance for industry. http://www.fda.gov/media/124907/download. Accessed 16 Mar 2020.

22. Medicines for Europe. Oncology - the new era for biosimilar medicines. September 8, 2017. https://www.medicinesforeur ope.com/news/oncology-the-new-era-for-biosimilar-medicines/. Accessed 17 Mar 2020.

23. European Medicines Agency and the European Commission. Biosimilars in the EU-Information guide for healthcare professionals (October 2019). https://www.ema.europa.eu/en/docum ents/leaflet/biosimilars-eu-information-guide-healthcare-profe ssionals_en.pdf. Accessed 17 Mar 2020.

24. Center for Biosimilars. Panel grapples with the role of biosimilars in oncology. Center for Biosimilars. June 1, 2018. https:// www.centerforbiosimilars.com/news/panel-grapples-with-therole-of-biosimilars-in-oncology. Accessed 12 Feb 2020.

25. U.S. Food and Drug Administration. Part 15 Public hearing on facilitating competition and innovation in the biological products marketplace. September 4, 2018. Meeting transcript, p 198. https://www.fda.gov/media/124899/download. Accessed 3 June 2020.

26. Sattler C. Center for Biosimilars. European pharmacovigilance for biosimilars is robust and provides meaningful information. Center for Biosimilars (June 12, 2018). https://www.centerforb iosimilars.com/contributor/carlos-sattler/2018/06/letter-to-theeditor-european-pharmacovigilance-for-biosimilars-is-robus t-and-provides-meaningful-information. Accessed 12 Feb 2020.

27. Vermeer NS, Giezen TJ, Zastavnik S, et al. Identifiability of biologicals in adverse drug reaction reports received from European clinical practice. Clin Pharmacol Ther. 2019;105(4):962-9.

28. Raffals LE, Nguyen GC, Rubin DT. Switching between biologics and biosimilars in inflammatory bowel disease. Clin Gastroentrol Heptol. 2019;17:818-23.

29. Kirkner RM. FDA's Gottlieb aims to end biosimilars groundhog day. Managed Care, January 15, 2019. https://www.managedcar emag.com/archives/2019/1/fda-s-gottlieb-aims-end-biosimilar s-groundhog-day. Accessed 18 May 2020.

30. Bruno E, Sadik K, Lafeuille MH, et al. Switching patterns among patients with chronic inflammatory diseases switching to an infliximab biosimilar or remaining on an originator infliximab. ACR/ARP Annual Meeting. 2019. Abstract 1115.

31. Alliance for Safe Biologic Medicines. Biosimilars 101. https:// safebiologics.org/biosimilars-101/. Accessed 17 Mar 2020.

32. Weise M, Bielsky MC, De Smet K, Ehmann F, Giezen TJ, Gravanis I, et al. Biosimilars: what clinicians should know. Blood. 2012;120:5111-7.

33. Murdoch B, Caulfield T. The law and ethics of switching from biologic to biosimilar in Canada. J Can Assoc Gastroenterol. 2020. https ://doi.org/10.1093/jcag/gwz043.

34. McKinnon RA, Cook M, Liauw W, et al. Biosimilarity and interchangeability: principles and evidence: a systematic review. BioDrugs. 2018;32(1):27-52.

35. Cohen HP, Blauvelt A, Rifkin RM, et al. Switching reference medicines to biosimilars: a systematic literature review of clinical outcomes. Drugs. 2018;78(4):463-78.

36. Milassin A, Fabian, Molnar T. Switching from infliximab to biosimilar in inflammatory bowel disease: overview of the literature and perspective. Ther Adv Gastroenterol. 2019;12:1-11. https://doi. org/10.1177/1756284819842748.

37. Barbier L, Ebbers H, Declerck P, et al. The efficacy, safety, and immunogenicity of switching between reference biopharmaceuticals and biosimilars-a systematic review. Clin Pharmacol Pharmacother. 2020. https://doi.org/10.1002/cpt.1836.

38. Kaplan GG, Ma C, Seow CH, et al. The argument against a biosimilar switch policy for infliximab in patients with inflammatory bowel disease living in Alberta. J Can Assoc Gastroenterol. 2020. https:// doi.org/10.1093/jcag/gwz044.

39. Kay J. Overcoming barriers to biosimilars in inflammatory arthritis. Nat Rev Rheumatol. 2020;16:65-6.

40. Gasteiger C, Dalbeth N, Petrie K. The effects of message framing on patients' perceptions and willingness to change to a biosimilar in a hypothetical drug switch. Arthritis Care Res. 2019. https://doi. org/10.1002/acr.24012.

41. Tweehuysen L, Huiskes VJB, van den Bemt BJF, et al. Higher acceptance and persistence rates after biosimilar transitioning in patients with a rheumatic disease after employing an enhanced communication strategy. Ann Rheum Dis. 2017. https://doi.org/10.1136/ annrheumdis-2017-eular.2889.

42. Rezk MF, Pieper B. To see or NOsee: the debate on the nocebo effect and optimizing the use of biosimilars. Adv Ther. 2018;35:749-53. https://doi.org/10.1007/s12325-018-0768-z.

43. Kristensen LE, Alten R, Puig L, et al. Non-pharmacological effects in switching medication: the nocebo effect in switching from originator to biosimilar agent. BioDrugs. 2018;32:397-404. https://doi. org/10.1007/s40259-018-0306-1.

44. Pouillon L, Danese S, Hart A, et al. Consensus report: clinical recommendations for the prevention and management of the nocebo effect in biosimilar-treated IBD patients. Aliment Pharmacol Ther. 2019;49:1181-7. https://doi.org/10.1111/apt.15223.

45. Glintborg B, Ibsen R, Bilbo REQ, Hetland ML, Kjelberg J. Does a mandatory non-medical switch from originator to biosimilar etanercept lead to increase in healthcare use and costs? A Danish registerbased study of patients with inflammatory arthritis. RMD Open. 2019. https://doi.org/10.1136/rmdopen-2019-001016.

46. Gibofsy A, Skup M, Mittal M, Johnson SJ, Davis M, Chao J, et al. Effects of non-medical switching on outcomes among patients prescribed tumor necrosis factor inhibitors. Curr Med Res Opin. 2017;33:1945-53.

47. Biosimilars Forum. Biosimilar FAQs. https://biosimilarsforum.org/ biosimilars-insights/biosimilars-faqs/. Accessed 18 May 2020.

48. Industry Standard Research Report. ASBM European Prescribers Survey. 2019. https://safebiologics.org/wp-content/uploads/2020/06/ EU-Survey-2019.pdf. Accessed 13 July 2020

49. Association for Affordable Medicines. Failure to launch-barriers to biosimilar market adoption. Sept 2019. https://www.biosimilar scouncil.org/wp-content/uploads/2019/09/AAM-Biosimilars-Counc il-Failure-to-Launch-2-web.pdf. Accessed 18 May 2020.

50. D’Amico F, Pouillon L, Argollo M, et al. Multidisciplinary management of the nocebo effect in biosimilar-treated IBD patients: results of a workshop from the NOCE-BIO consensus group. Dig Liver Dis. 2020;52(2):138-42. https://doi.org/10.1016/j.did.2019.11.004.

51. Joint Statement of the Food and Drug Administration and the Federal Trade Commission regarding a collaboration to advance competition in the biologics marketplace. Feb 3, 2020. https://www.fda. gov/media/134864/download. Accessed 17 Mar 2020.

52. US Food and Drug Administration. Promotional labeling and advertising considerations for prescription biological reference and biosimilar products: questions and answers-guidance for industry. https ://www.fda.gov/media/134862/download. Accessed 17 Mar 2020.

53. ICMRA statement about confidence in biosimilar products (for healthcare professionals). July 2019. http://www.icmra.info/drupa 1/sites/default/files/2019-07/ICMRA_statement_about_confidence _in_biosimilar_product_HCP.PDF. Accessed 17 Mar 2020.

54. Heavner BB and Judson KR. A new guide for promotional labeling and advertising of biosimilar products. Center for Biosimilars (May 26, 2020) https://www.biosimilardevelopment.com/doc/a-new-guide -for-promotional-labeling-and-advertising-of-biosimilar-products0001. Accessed 26 May 2020.

55. US Food and Drug Administration. Biosimilars are safe, effective treatment options. https://www.fda.gov/drugs/therapeutic-biologicsapplications-bla/biosimilars. Accessed 17 Mar 2020. 
56. European Medicines Agency. Questions and answers for patientsbiosimilars medicines explained. http://ec.europa.eu/DocsRoom/ documents/26643. Accessed 17 Mar 2020.

57. Bridges SL Jr, White DW, Worthing AB, On behalf of the American College of Rheumatology, et al. The science behind biosimilars: entering a new era of biologic therapy. Arthritis Rheumatol. 2018;70(3):334-44.

58. Lyman GH, Balaban E, Diaz M, et al. American Society of Clinical Oncology statement: biosimilars in Oncology. J Clin Oncol. 2018;36:1260-5. https://doi.org/10.1200/jco.2017.77.4893.

59. Academy of Managed Care Pharmacy. Biosimilars Resource Center. https://www.biosimilarsresourcecenter.org/. Accessed 17 Mar 2020.

60. Arthritis Foundation. Biosimilars: what you should know. https:// arthritis.org/drug-guide/medication-topics/biosimilars-an-alternativ e-to-biologics. Accessed 17 Mar 2020.

61. American Cancer Society-Cancer Action Network. Understanding biologic and biosimilar drugs. https://www.fightcancer.org/polic y-resources/understanding-biologic-and-biosimilar-drugs. Accessed 17 Mar 2020.

62. Biosimilars Forum. Biosimilars: a new era in medicine. https://biosi milarsforum.org/. Accessed 17 Mar 2020.

63. Biosimilars Council. Biosimilars 101. https://biosimilarscouncil.org/ biosimilars-101/. Accessed 17 Mar 2020.

64. Crespi-Lofton J, Skelton JB. The growing role of biologics and biosimilars in the United States: perspectives from the
APhA biologics and biosimilars stakeholder conference. J Am Pharm Assoc. 2017;57(5):e15-27. https://doi.org/10.1016/j. japh.2017.05.014.

65. International Alliance of Patient Organizations. Biologic medicines toolkit 2017. https://www.iapo.org.uk/biosimilars-toolkit. Accessed 15 May 2020.

66. US Food and Drug Administration. Biosimilar basics. 2019. https:// www.fda.gov/media/130918/download. Accessed 15 May 2020.

67. US Food and Drug Administration. What is a biosimilar? 2019. https ://www.fda.gov/media/108905/download. Accessed 15 May 2020.

68. Tan SS, Goonawardene N. Internet health information seeking and the patient-physician relationship: a systematic review. J Med Internet Res. 2017;19(1):e9. https://doi.org/10.2196/jmir.5729.

69. Pew Research Center. Health online 2013. https://www.pewresearc h.org/internet/2013/01/15/health-online-2013-2/. Accessed 17 Mar 2020.

70. IQVIA Report. The impact of Biosimilar Competition in Europe. 2018.

71. Mehr S. An interesting comparison: the latest data on US and EU biosimilar uptake. Biosimilars Research and Review. April 23, 2020. https://biosimilarsrr.com/2020/04/23/an-interesting-compa rison-the-latest-data-on-us-and-eu-biosimilar-uptake/. Accessed 18 May 2020. 